\title{
Strain-deformation Reconstruction of Carbon Fiber Composite Laminates Based on BP Neural Network
}

\author{
Guoping Ding ${ }^{a, b} \bigoplus^{*}$, Siyuan Jiang ${ }^{c}$, Songchao Zhang ${ }^{c}$, Jieliang Xiao ${ }^{c}$ \\ ${ }^{a}$ Institute of Advanced Material and Manufacturing Technology, Wuhan University of Technology, \\ Wuhan 430070 \\ ${ }^{b}$ Hubei Key Laboratory of Digital Manufacturing, Wuhan University of Technology, Wuhan 430070 \\ ${ }^{c}$ School of Mechanical and Electrical Engineering, Wuhan University of Technology, Wuhan 430070
}

Received: June 20, 2019; Revised: August 13, 2019; Accepted: October 2, 2019

\begin{abstract}
The Carbon Fiber Reinforced Polymer (CFRP) laminate structural components used in the aerospace and military domains require high precision and strong stability. Usually the deformation of these structural components is difficult to be measured directly during operation, but the deformation of the CFRP laminate structure can be reconstructed with strain information. The CFRP laminate structure can be designed to adapt to the requirements of different applications through layering of variable thickness. In this paper, aiming at the discontinuous stiffness and strength of the variable laminations within the CFRP laminate structure, the BP neural network is proposed to be applied to the deformation reconstruction of CFRP laminates. With strain as input and deformation as output, based on a large amount of experimental data, the BP neural network model between strain and deformation is obtained through training. In this paper, CFRP test piecs with equal thickness and variable thickness were designed, and the corresponding strain-deformation reconstruction experimental system was constructed. The strain on the surface of CFRP test piece was measured by the fiber grating sensor, and the deformation of the test piece was measured by the laser displacement sensor. The comparative analysis between the predicted deflection obtained by neural network reconstruction and the actual measured deflection shows that BP neural network can reconstruct the structural deformation of CFRP laminates within certain error range.
\end{abstract}

Keywords: CFRP laminates, deformation reconstruction, BP neural network, strain, fiber grating sensor.

\section{Introduction}

Carbon Fiber Reinforced Polymer (CFRP) has the advantages of high specific strength, good damping performance and flexible designability and the CFRP laminate structure is one of the most common structures of CFRP materials. To meet the bearing and weight reduction requirements on different occasions, CFRP laminates often adopt the variable thickness structure, and the thickness can be changed by interrupting one or several layers in a single-layer sheet inside the structure ${ }^{1-3}$. At present, laminate structure is widely used in military, aerospace and wind power generation fields where quality and noise reduction performance are required. The CFRP aircraft wings, propeller blades and wind turbine blades are mostly of the variable thickness structure, whose shapes have requirements on high precision and strong stability since the deformation of the structure will affect their performance and bearing capacity, resulting in significant damage ${ }^{4-6}$. Often, the deformation of these structural components are difficult to be measured directly in operation using photography or laser technology. To clearly understand the deformation of CFRP laminate structures under certain load conditions, indirect measurement of deformation is available. For example, the

*e-mail: wutfbg@163.com deformation reconstruction of CFRP laminate structures can be performed based on strain information ${ }^{7-8}$.

At present, many scholars have proposed a variety of strain-based deformation reconstruction theories and conducted feasibility verification analysis, including inverse finite element method, structural curvature method and Ko displacement theory. The inverse finite element method can realize the transformation of surface strain and displacement of the structure. Through years of research and development by scholars such as Tessler A from NASA Research Center, the inverse finite element deformation reconstruction theory is applied to the truss, beam and frame structures, and the measured surface strain data are used to reconstruct the three-dimensional displacement field of truss, beam and frame structures ${ }^{9-11}$. However, the application of this method in the CFRP laminate structure requires the measurement of internal strain of the laminate, which is difficult. Meanwhile, the programming of the inverse finite element method and the construction of the inverse elements are complicated. The workload is large. which makes it impossible to achieve the real-time monitoring of deformation ${ }^{12-14}$. Based on the analysis of the transforming relation between discrete strain and discrete curvature information, the structural curvature method explores the reconstruction algorithm of space 
complex curved surface. However, this method transforms the strain information on structureal surface into the curvature information so as to reconstruct the deformation of structure, which is more suitable for large-area flexible plate structures $^{15-17}$. Scholars such as William L. Ko of the NASA Flight Research Center proposed the Ko Displacement Theory in 2007, which was initially applied in engineering. Based on the classical hypothesis of material mechanics and the geometrical and physical relations of beam structure deformation, Ko displacement theory is to discretize the overall structure of the beam, assuming that in each section, the strain is linearly distributed along the length direction; using the partial derivative relationship between the strain and displacement function, the deformation in the area is solved through the integral of strain, and the overall deformation of the structure is reconstructed by integrating the deformation information in each area in combination with the coordination relations ${ }^{18}$. For the CFRP laminate structure with variable thickness, an area of stress concentration will be generated in the transition region inside the structure. Where the stiffness and strength of the structure are discontinuous, the force condition is more complicated. The relation between strain and deformation cannot be established under the classical material mechanical hypothesis. Therefore, Ko displacement theory is not applicable to the deformation reconstruction of CFRP variable-thickness laminate structures ${ }^{19-20}$. Thus, the application of the above methods to the deformation reconstruction of CFRP variable thickness laminate structure has certain limitations.

In addition to the strain-based method, there is also a method of reconstructing the deformation of the laminate according to numerical analysis. In India, Hirwani CK and other scholars established a finite element model of carbon fiber composite laminated curved shell plates based on two higher-order kinematic models and GreenLagrange nonlinear strain-displacement relationships. An original MATLAB code was developed and proved. The mathematical model can reconstruct the nonlinear deflection value under different loading states ${ }^{21-22}$.In recent years, with the continuous development of machine learning, artificial neural networks have been widely used to solve problems encountered in the development of materials engineering. Under the specific mapping relationship between ambiguous data, artificial neural networks propose a nonlinear mathematical form that can accurately predict data trends ${ }^{23}$. BP neural network is a typical algorithm in artificial intelligence networks .The BP neural network has a simple topology with high error precision, programming ease, strong operability and wide applications ${ }^{24}$. At present, BP neural network monitoring structural deformations are mostly used for the safety and health monitoring in large-scale engineering structures, such as the displacement prediction of dams, deformation monitoring of pipeline engineering and that of bridge tunnel engineering ${ }^{25-26}$.
In this paper, the BP neural network was proposed to be applied to the deformation reconstruction of CFRP laminate structures. With the CFRP equal-thickness and variablethickness laminates as the study objects, in the case of bending deformation of the CFRP laminate structure, there was certain relation between the strain and deformation. When the function was unknown, the surface strain of the structure served as the input and the deformation as the output, the BP neural network model was established. Based on the experiment, $\mathrm{N}$ sets of strain-deformation data were collected and input into the model. Through certain training and learning, the model can reconstruct the flexibility deformation of laminates based on the strain information of CFRP laminates, and the error of output deformation data and the expected values reached the target setting range.

\section{Principles of the Deformation Reconstruction Based on the BP Neural Network Algorithm}

The BP neural network is a multi-layered feedforward neural network whose training mode has two processes: the forward propagation of the signal and the back propagation of the error. The BP neural network model is as shown in Figure 1, including the input layer $x_{\mathrm{i}}$, the hidden layer $h_{\mathrm{i}}$ and the output layer $y_{\mathrm{i}}, W_{\mathrm{ij}}$ and $a_{\mathrm{j}} 、 W_{\mathrm{jk}}$ and $b_{\mathrm{k}}$ represent the weights and thresholds of the input layer to the hidden layer, the hidden layer to the output layer, respectively.

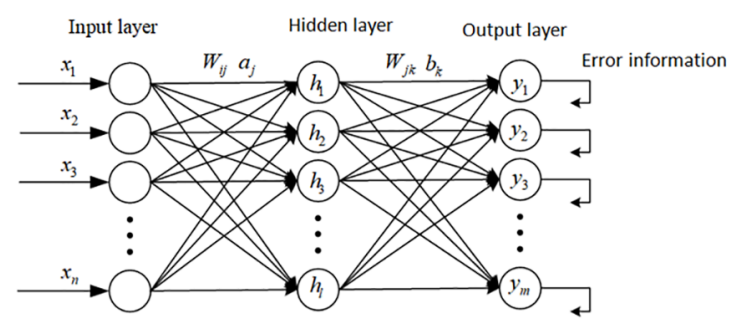

Figure 1. Schematic Diagram of BP Neural Network Model

The output results in Figure 1 can be seen as the nonlinear function of the input vector and the specific calculation is as follows:

$$
n e t=w_{1} x_{1}+w_{2} x_{2}+w_{3} x_{3}+\cdots+w_{n} x_{n}+a
$$

Where: $\mathrm{w}_{1}, \mathrm{w}_{2}, \mathrm{w}_{3}, \cdots+\mathrm{w}_{\mathrm{n}}$ represents the connection weight of each neuron corresponding to the neurons in the upper layer; $\mathrm{x}_{1}, \mathrm{x}_{2}, \mathrm{x}_{3} \cdots, \mathrm{x}_{\mathrm{n}}$ represents the input data of neurons in the upper layer; a represents the threshold of neurons in the layer. The output value of each neuron node is realized according to the output value of all nodes in the previous layer, the connection weight of the current nodes and all nodes in the upper layer, the threshold of the current nodes as well as the activation function. $f$ represents an activation 
function, also called a transfer function. As an activation function, two conditions must be met, that is, the function can be derived and be a monotonically increasing function. The activation function used in this paper is the Sigmoid function that comes with MATLAB as shown in Equation (2).

$$
f(n e t)=\frac{1}{1+e^{-n e t}}
$$

It is easy to know that the range of the activation function is $(0,1)$, and it can be derived. The range of the derivative is $(0,0.25)$, and the derivative takes the maximum value when 0 is taken. The implementation steps of the BP neural network learning method are as follows : Firstly, the BP neural network was initialized. Assign a random number between $(-1,1)$ to the weight and threshold ,the global error target value $\varepsilon$, the iterations $Q$ and the learning efficiency $\eta$ were set. A set of input layer vectors $\mathrm{X}(\mathrm{x} 1, \mathrm{x} 2, \ldots, \mathrm{xn})$ and expected output vectors $\mathrm{T}(\mathrm{t} 1, \mathrm{t} 2, \cdots, \mathrm{tm})$ were randomly extracted from the $\mathrm{N}$ sets of learning samples; weights $\mathrm{W}_{i j}$, Wjk and threshold values aj, bk were initialized and substituted into the activation function respectively so that the hidden layer $\mathrm{H}(\mathrm{h} 1, \mathrm{~h} 2, \cdots, \mathrm{hl})$ and the output layer vector $\mathrm{Y}(\mathrm{y} 1, \mathrm{y} 2, \cdots, \mathrm{ym})$ were calculated with the expressions as shown in (3) and (4), where 1 was the number of nodes in the hidden layer and $\mathrm{f}$ was the activation function.

$$
\begin{gathered}
h_{j}=f\left(\sum_{i=1}^{n} w_{i j} x_{i}-a_{j}\right) j=1,2, \cdots, l \\
y_{k}=f\left(\sum_{j=1}^{l} h_{j} w_{j k}-b_{k}\right) k=1,2, \cdots, m
\end{gathered}
$$

The neural network prediction error e is calculated according to the network prediction output vector $\mathrm{Y}(\mathrm{y} 1, \mathrm{y} 2, \cdots, \mathrm{ym})$ and the expected output value $\mathrm{T}(\mathrm{t} 1, \mathrm{t} 2, \cdots$ , tm), and then the connection weights of the input layer to the hidden layer and the hidden layer to the output layer can be corrected according to the error term e, error e is a function of $W_{\mathrm{ij}}$. The learning efficiency $\eta$ is needed in the correction process, and the learning efficiency can be regarded as the learning step, that is, the span of the weight and the threshold in the adjustment process. After the correction, the expression of the global error E can be obtained as shown in Equation 5.

$$
E=\frac{1}{2 Q} \sum_{p=1}^{Q} \sum_{k=1}^{m}\left(t_{p k}-y_{p k}\right)^{2}
$$

Where $p$ represented the number of network iterations, when $E<\varepsilon$, or the number of iterations p reached Q times, the algorithm ended. If not, a set of learning samples were randomly selected from the residual samples and input into the neural network for learning of the next round until the global error was less than the target value or the number of iterations reached the set value. Figure 2 shows the BP neural network algorithm learning process.

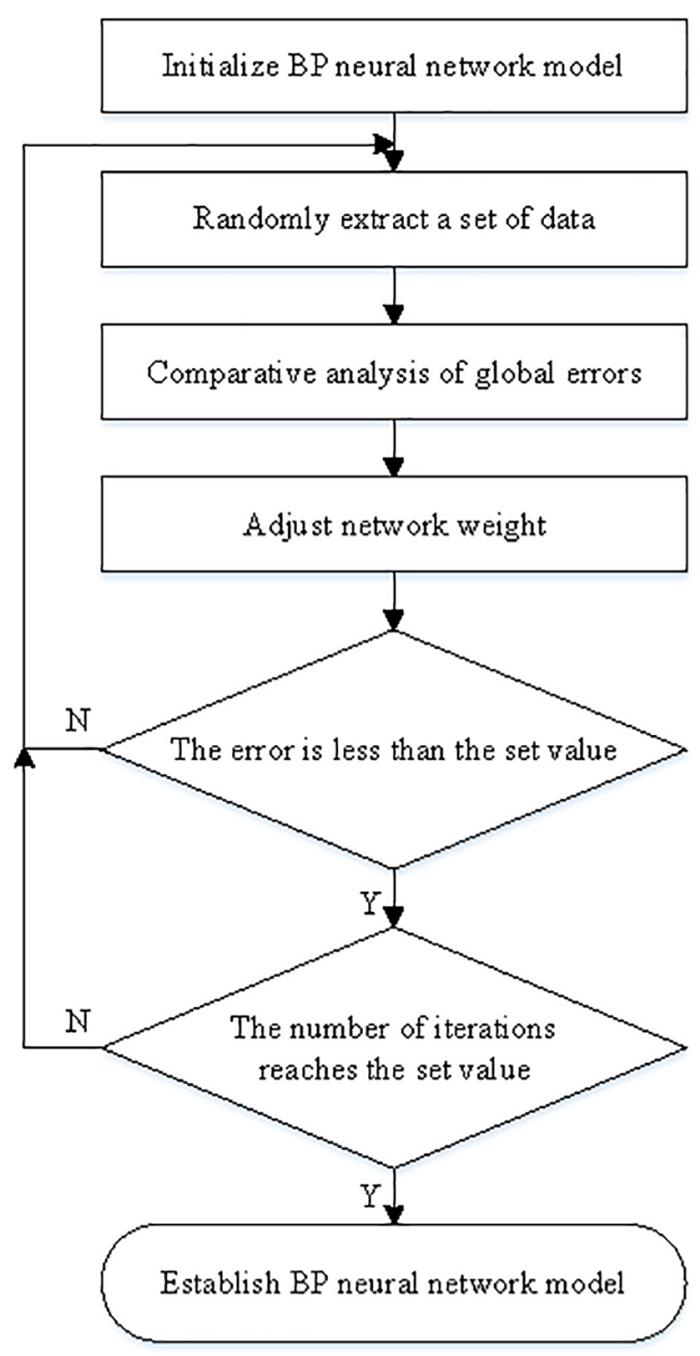

Figure 2. BP Neural Network Algorithm Learning Process

\section{Deformation Reconstruction Experiment of the Strain-based CFRP Laminate}

In this experiment, a strain-based experimental system for CFRP laminate deformation reconstruction was constructed. The CFRP laminate test pieces with equivalent thickness and variable thickness were loaded by a universal tesing machine, and the strain of multiple nodes on the surface of CFRP laminate was measured with the fiber grating sensor. The deflection of the corresponding node was measured by the laser displacement sensor.

In the experiment, 45 sets of strain-deflection experimental data were collected as the training samples of the BP neural network model, and the strain-deflection BP neural network models of laminate structures with equal thickness and variable thickness were established respectively using the BP neural network algorithm toolbox in MATLAB. The BP neural network was further trained with the experimental sample data until the number of iterations reached the 
set value or the root mean square error was less than the target value. Once the BP neural network model was successfully constructed.Then, another set of equal thickness and variable thickness laminate strain data collected is substituted into the respective BP neural network models to reconstruct the predicted deflection value. Finally, the predicted deflection obtained through BP neural network reconstruction was compared with the actual measured deflection value to verify the feasibility of the BP neural network applied to the deformation reconstruction study of CFRP laminate structure.

\subsection{Design and preparation of CFRP laminate test pieces}

In this experiment, two sets of CFRP laminates test pieces with equal thickness and variable thickness were designed. For the convenience of describing the test pieces, the two laminates of equal thickness were named as test pieces A1 and A2. The layering parameters were set as $\left[0_{2} / \pm 45 / 0_{2} / \pm 45 / 0_{3}\right]_{\mathrm{s}}$ with 22 layers in total; a thickness of $0.2 \mathrm{~mm}$ per layer and the overall thickness of the model was $4.2 \mathrm{~mm}$. The two laminates of variable thickness were named as test pieces B1 and B2, and the CFRP variable thickness laminate was realized by the drop of layering. The slope continuous transition was adopted by the layering dropping area where the thickest layering parameters were set as $\left[0_{2} / \pm 45 / 0_{2} / \pm 45 / 0_{3}\right]$ s totalling 22 layers and the thinnest layering parameters as $\left[0_{2} / \pm 45 / \pm 45 / 0\right]_{\mathrm{s}}$ with 14 layers in total, each layer had a thickness of $0.2 \mathrm{~mm}$, the thickest thickness $4.2 \mathrm{~mm}$ and the thinnest $2.8 \mathrm{~mm}$. Each time the layer was dropped, the upper and lower layers were symmetrically oriented in the $0^{\circ}$ direction, and symmetric layering was assured. Figure 3 shows the schematic diagram of dropping layering for the laminate with variable thickness.

In this experiment, the prepreg material produced by Zhongfu Shenying Carbon Fiber Co., Ltd. was used to prepare the carbon fiber/epoxy composite laminates through the autoclave molding process. The composition of the prepreg was mainly T700 carbon fiber and epoxy resin.
Table 1 shows the cut size of the test piece prepreg. Figure 4 shows the prepared test piece.

\subsection{Experimental system}

The experimental system was as shown in Figure 5. The CFRP test piece was fixed on the upper end face of the I-shaped support with steel plates and bolts to form a cantilever construction; the I-shaped support was fixed on the universal testing machine with two G-shaped clamps, and load was applied to the CFRP test pieces with the universal testing machine of the model DNS100. Six fiber grating sensors were attached along the center line of the CFRP test pieces to measure the strain. The FBG sensor has a diameter of $125 \mu \mathrm{m}$, a length of about $10 \mathrm{~mm}$ with the center wavelength around $1550 \mathrm{~nm}$. The wavelength deviation of the FBG sensor was demodulated and recorded by the MOI S130 demodulator. The deformation of CFRP test pieces was measured by the laser displacement sensor. The sensor head model was Omron ZX2-LD100, the measurement range was $100 \pm 35 \mathrm{~mm}$, the measurement accuracy was $5 \mu \mathrm{m}$, and the linearity was $\pm 0.1 \%$.

\subsection{Experimental procedures}

\subsubsection{Experimental data collection}

First the initial wavelength of the FBG sensor and the initial readings of the deflection measurement node by the laser displacement sensor were recorded; the loading steps, and holding for $90 \mathrm{~s}$ every $0.5 \mathrm{~mm}$; the central wavelength of the FBG sensors during the maintenance was saved for once. The laser displacement sensors measured the deflection of the measurement nodes for once until the load was applied to $25 \mathrm{~mm}$, with 50 loading stages in total plus 50 sets of strain-deflection data. The wavelength shifts and changes in deflection of the FBG sensors for each loading stage were calculated, and the strain on the surface of the test piece was calculated according to the strain sensitivity of the FBG sensors.

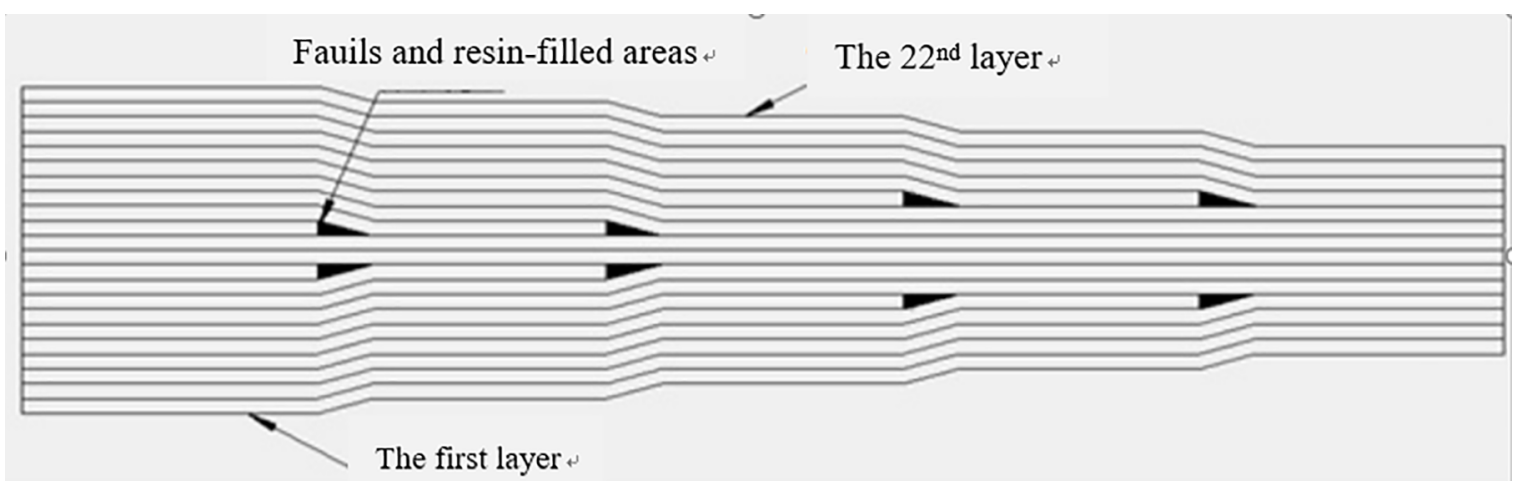

Figure 3. Schematic Diagram of Dropping Layering of CFRP Variable Thickness Laminates 
Table 1. Prepreg Cutting Size of Laminates. A Sizes of Laminates A1 and A2 with Equal thickness, B Sizes of Laminates B1 and B2 with Variable thickness

A

\begin{tabular}{|c|c|c|c|}
\hline $\begin{array}{l}\text { Number } \\
\text { of Prepreg } \\
\text { Tapes }\end{array}$ & $\begin{array}{c}\text { Angle of } \\
\text { Layering }\end{array}$ & $\begin{array}{c}\text { Width of } \\
\text { Prepreg } \\
\text { Tapes } \\
(\mathbf{m m})\end{array}$ & $\begin{array}{c}\text { Length of } \\
\text { Prepreg } \\
\text { Tapes } \\
(\mathrm{mm})\end{array}$ \\
\hline 1 & $0^{\circ}$ & 70 & 400 \\
\hline 2 & $0^{\circ}$ & 70 & 400 \\
\hline 3 & $-45^{\circ}$ & 70 & 400 \\
\hline 4 & $45^{\circ}$ & 70 & 400 \\
\hline 5 & $0^{\circ}$ & 70 & 400 \\
\hline 6 & $0^{\circ}$ & 70 & 400 \\
\hline 7 & $-45^{\circ}$ & 70 & 400 \\
\hline 8 & $45^{\circ}$ & 70 & 400 \\
\hline 9 & $0^{\circ}$ & 70 & 400 \\
\hline 10 & $0^{\circ}$ & 70 & 400 \\
\hline 11 & $0^{\circ}$ & 70 & 400 \\
\hline 12 & $0^{\circ}$ & 70 & 400 \\
\hline 13 & $0^{\circ}$ & 70 & 400 \\
\hline 14 & $0^{\circ}$ & 70 & 400 \\
\hline 15 & $45^{\circ}$ & 70 & 400 \\
\hline 16 & $-45^{\circ}$ & 70 & 400 \\
\hline 17 & $0^{\circ}$ & 70 & 400 \\
\hline 18 & $0^{\circ}$ & 70 & 400 \\
\hline 19 & $45^{\circ}$ & 70 & 400 \\
\hline 20 & $-45^{\circ}$ & 70 & 400 \\
\hline 21 & $0^{\circ}$ & 70 & 400 \\
\hline 22 & $0^{\circ}$ & 70 & 400 \\
\hline
\end{tabular}

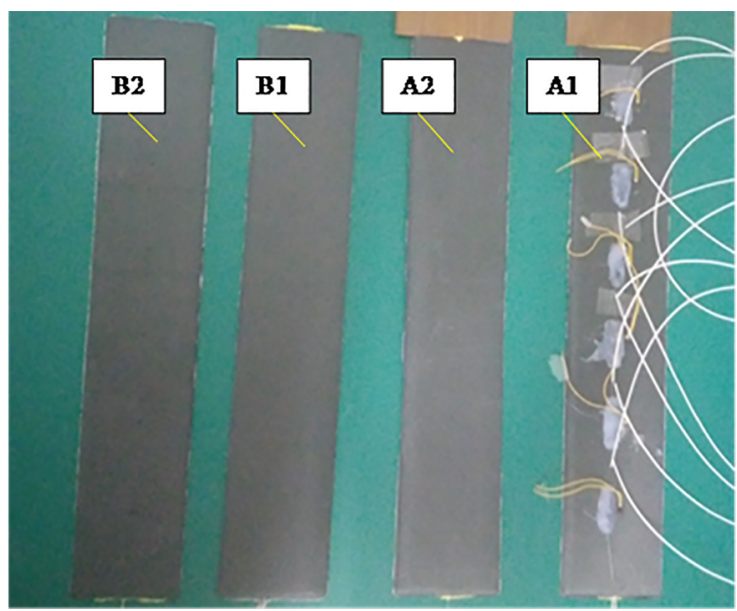

Figure 4. Prepared Test Piece of Equal Thickness and Variable Thickness Laminates

\begin{tabular}{|c|c|c|c|}
\hline \multicolumn{4}{|c|}{ B } \\
\hline $\begin{array}{l}\text { Number } \\
\text { of Prepreg } \\
\text { Tapes }\end{array}$ & $\begin{array}{c}\text { Angle of } \\
\text { Layering }\end{array}$ & $\begin{array}{c}\text { Width of } \\
\text { Prepreg } \\
\text { Tapes } \\
(\mathbf{m m})\end{array}$ & $\begin{array}{c}\text { Length of } \\
\text { Prepreg } \\
\text { Tapes } \\
(\mathrm{mm})\end{array}$ \\
\hline 1 & $0^{\circ}$ & 70 & 400 \\
\hline 2 & $0^{\circ}$ & 70 & 400 \\
\hline 3 & $-45^{\circ}$ & 70 & 400 \\
\hline 4 & $45^{\circ}$ & 70 & 400 \\
\hline 5 & $0^{\circ}$ & 70 & 300 \\
\hline 6 & $0^{\circ}$ & 70 & 240 \\
\hline 7 & $-45^{\circ}$ & 70 & 400 \\
\hline 8 & $45^{\circ}$ & 70 & 400 \\
\hline 9 & $0^{\circ}$ & 70 & 180 \\
\hline 10 & $0^{\circ}$ & 70 & 120 \\
\hline 11 & $0^{\circ}$ & 70 & 400 \\
\hline 12 & $0^{\circ}$ & 70 & 400 \\
\hline 13 & $0^{\circ}$ & 70 & 120 \\
\hline 14 & $0^{\circ}$ & 70 & 180 \\
\hline 15 & $45^{\circ}$ & 70 & 400 \\
\hline 16 & $-45^{\circ}$ & 70 & 400 \\
\hline 17 & $0^{\circ}$ & 70 & 240 \\
\hline 18 & $0^{\circ}$ & 70 & 300 \\
\hline 19 & $45^{\circ}$ & 70 & 400 \\
\hline 20 & $-45^{\circ}$ & 70 & 400 \\
\hline 21 & $0^{\circ}$ & 70 & 400 \\
\hline 22 & $0^{\circ}$ & 70 & 400 \\
\hline
\end{tabular}

\subsubsection{Creation and training of the BP neural network model}

Using the existing BP neural network algorithm toolbox in MATLAB, the BP neural network model of strain-deflection of laminated plate structures is established. There were six strain detection nodes and five deflection measurement nodes on each test piece. The number of nodes in the input layer was set as 6 , the number of nodes in the output layer as 5 , the number of nodes in the hidden layer as 8 , the number of iterations as 100 , the learning rate as 0.1 , and the target value of the root mean square error as 0.0005 . The 45 sets of strain-deflection data of equal thickness and variable thickness structures were randomly extracted and collected as the training samples respectively later, the other 5 sets of data are used as test data. the weights and thresholds of the 


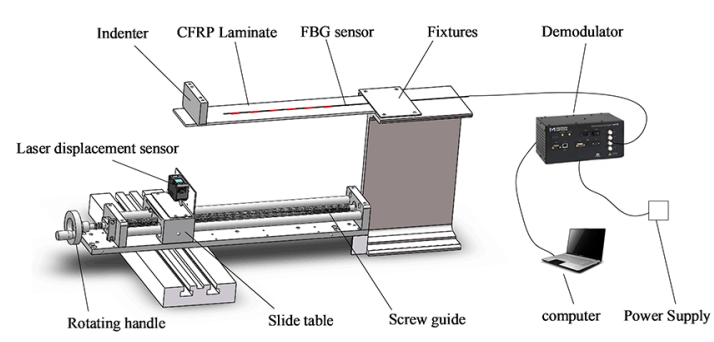

a
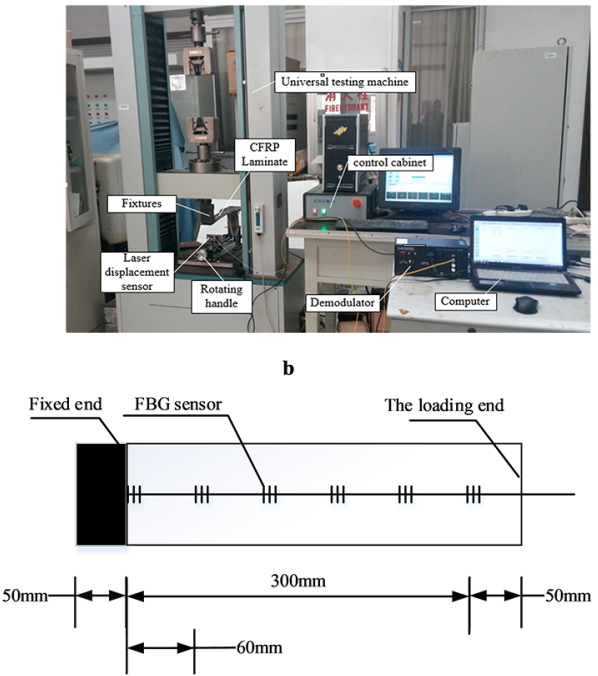

c

Figure 5. Experimental System of the Strain-based CFRP Laminate Deformation Reconstruction. a Schematic Diagram of the Experimental System,b Site Map of Experimental System,c Paste Position of the FBG Sensors
BP neural network were initialized, a set of data randomly selected, and the strain data were substituted into the model for the calculation of the predicted deflection value. By a comparison with the actual deflection value, the root mean square error between the two was calculated, and the weight and threshold of the network were adjusted according to the root mean square error. If the root mean square error was smaller than the target value, the next set of data was randomly selected from the residual training samples and substituted into the model for recalculation until the number of iterations reached the set value or the root mean square error was less than the target value. By this time the cycle was terminated and the strain-deformation BP neural network model for the test piece structure was obtained.

After the BP neural network models with equal thickness and variable thickness were established, the strain data of the test pieces A2 and B2 were substituted into their respective BP network models to calculate the predicted deflection values.

\subsection{Experimental results}

Table 2 shows the analysis summary of the strain values, measured deflection values and predicted deflection values of $\mathrm{A} 1$ and $\mathrm{A} 2$, B1 and B2 under the same loading conditions.

To analyze the error between measured deflection value and predicted deflection value of the laminate structure of the same layering, and to further study the BP neural network, the curve fitting of the two layering schemes was drawn as shown in Figure 6

In this paper, the root mean square error RMS between the actual deflection value and the predicted deflection

Table 2. Comparison of Measured Deflection Values and Predicted Deflection Values of the Test Pieces. A D Measured Deflection Value and Predicted Deflection Value of Test Piece A1、B1、A2、B2, respectively

A

A1

\begin{tabular}{lccc}
\hline $\begin{array}{l}\text { Distance to } \\
\text { the Fixed } \\
\text { End/mm }\end{array}$ & Strain/ $\boldsymbol{\mu \varepsilon}$ & $\begin{array}{l}\text { Measured } \\
\text { Deflection } \\
\text { Value } / \mathbf{m m}\end{array}$ & $\begin{array}{c}\text { Predicted } \\
\text { Deflection } \\
\text { Value /mm }\end{array}$ \\
\hline 0 & 803.23 & -- & -- \\
60 & 627.63 & -1.557 & -1.590 \\
120 & 508.25 & -4.473 & -4.514 \\
180 & 370.04 & -8.132 & -8.038 \\
240 & 223.29 & -12.368 & -12.365 \\
300 & 72.96 & -16.824 & -16.803 \\
\hline
\end{tabular}

C

A2

\begin{tabular}{lccc}
\hline $\begin{array}{l}\text { Distance to } \\
\text { the Fixed } \\
\text { End/mm }\end{array}$ & Strain/ $\mathbf{\mu \varepsilon}$ & $\begin{array}{c}\text { Measured } \\
\text { Deflection } \\
\text { Value } / \mathbf{m m}\end{array}$ & $\begin{array}{c}\text { Predicted } \\
\text { Deflection } \\
\text { Value } / \mathbf{m m}\end{array}$ \\
\hline 0 & 880.38 & -- & -- \\
60 & 749.91 & -1.808 & -1.544 \\
120 & 577.09 & -4.74 & -4.498 \\
180 & 403.51 & -9.044 & -8.183 \\
240 & 233.33 & -13.348 & -12.452 \\
300 & 86.80 & -17.758 & -16.710 \\
\hline
\end{tabular}

B

B1

\begin{tabular}{cccc}
\hline $\begin{array}{c}\text { Distance to } \\
\text { the Fixed } \\
\text { End/mm }\end{array}$ & Strain/ $\boldsymbol{\mu \varepsilon}$ & $\begin{array}{c}\text { Measured } \\
\text { Deflection } \\
\text { Value } / \mathbf{m m}\end{array}$ & $\begin{array}{c}\text { Predicted } \\
\text { Deflection } \\
\text { Value } / \mathbf{m m}\end{array}$ \\
\hline 0 & 692.75 & -- & -- \\
60 & 577.36 & -0.953 & -0.945 \\
120 & 532.44 & -3.427 & -3.322 \\
180 & 485.74 & -6.197 & -6.123 \\
240 & 396.30 & -10.13 & -10.197 \\
300 & 162.89 & -15.489 & -15.481 \\
\hline
\end{tabular}

D

B2

\begin{tabular}{cccc}
\hline $\begin{array}{c}\text { Distance to } \\
\text { the Fixed } \\
\text { End/mm }\end{array}$ & Strain/ $\boldsymbol{\mu \varepsilon}$ & $\begin{array}{c}\text { Measured } \\
\text { Deflection } \\
\text { Value } / \mathbf{m m}\end{array}$ & $\begin{array}{c}\text { Predicted } \\
\text { Deflection } \\
\text { Value } / \mathbf{m m}\end{array}$ \\
\hline 0 & 651.12 & -- & -- \\
60 & 519.99 & -1.047 & -0.810 \\
120 & 511.49 & -3.075 & -3.447 \\
180 & 447.72 & -6.03 & -6.195 \\
240 & 356.63 & -10.52 & -10.025 \\
300 & 176.02 & -15.4 & -15.465 \\
\hline
\end{tabular}




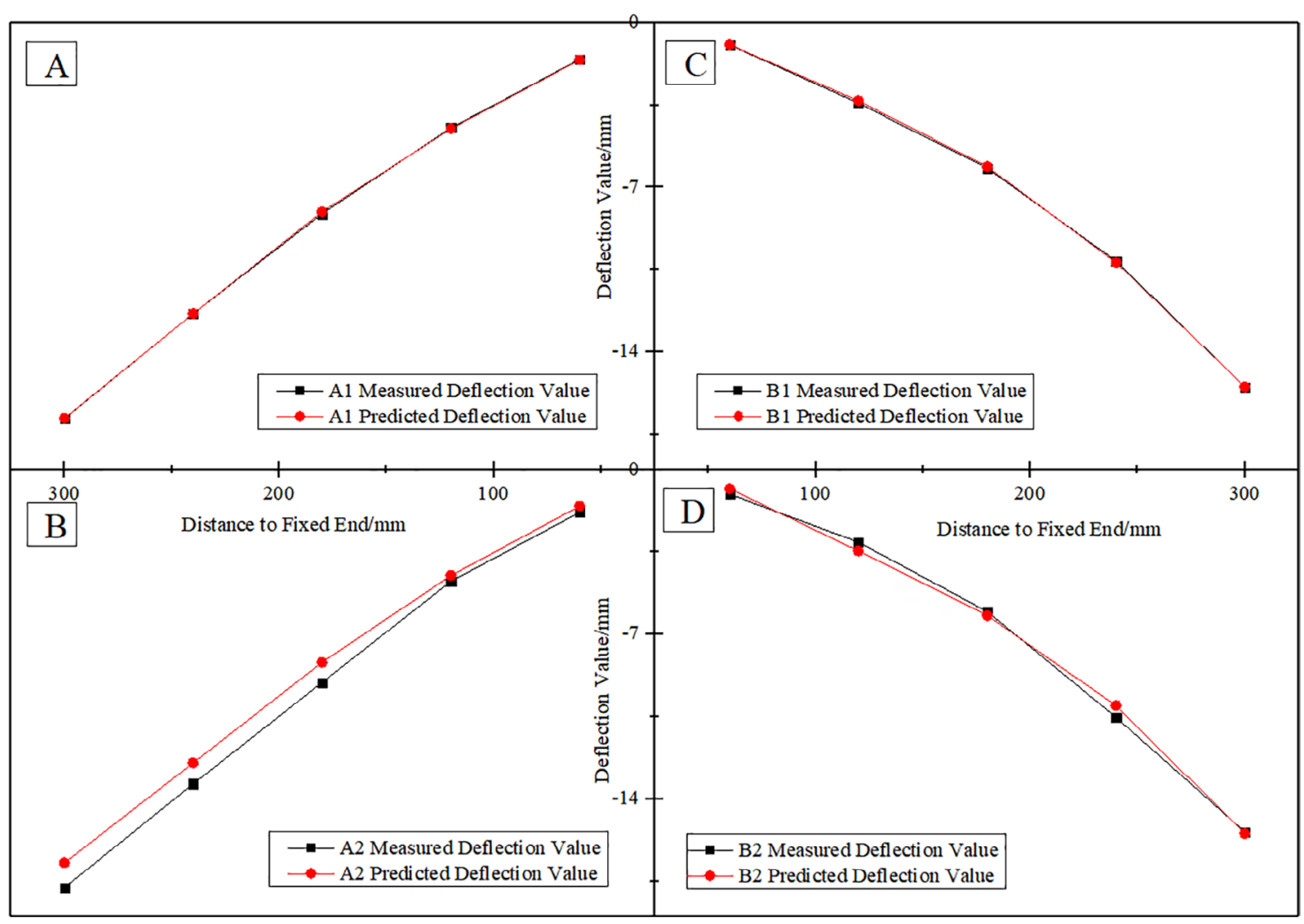

Figure 6. Curve Fitting Diagrams of Actual Measured Deflection Value and Predicted Deflection Value of the Test Pieces. A D Fitting Diagram of Test PieceA1、A2、B1、B2,respectively

output value of the test piece was used to evaluate the error between the two. The calculation formula of RMS is as shown in Equation 6.

$$
R M S=\sqrt{\frac{\sum_{i=1}^{n}\left(y_{i}^{\prime}-y_{i}\right)^{2}}{n}}
$$

Where $y_{i}^{\prime}$ is the actual deflection value of the laminate structure, $y_{i}^{\prime}$ reflects the predicted deflection value, and $n$ is the number of strain collection nodes.

The calculation results are as shown in Table 3.

Table 3. Root Mean Square Error of Actual Deflection Value and Predicted Deflection Value of the Test Piece

\begin{tabular}{ccccc}
\hline & A1 & A2 & B1 & B2 \\
\hline RMS $/ \mathrm{mm}$ & 0.1098 & 1.6645 & 0.1453 & 0.6863 \\
\hline
\end{tabular}

\section{Discussion}

As can be seen from Figure 4 that the actual deflection value and the predicted deflection value of the test pieces $\mathrm{A} 1$ and $\mathrm{B} 1$ agree better than the test pieces $\mathrm{A} 2$ and $\mathrm{B} 2$. It is seen from Table 3 that the actual deflection value and the predicted deflection value of the test pieces $\mathrm{A} 1$ and $\mathrm{B} 1$ have few errors, but the errors between the actual deflection value and the predicted deflection value of the test pieces $\mathrm{A} 2$ and $\mathrm{B} 2$ are large. Because the training samples of the BP neural network model used to construct the two types of layering structures were experimental data measured under certain loading conditions with $\mathrm{A} 1$ and $\mathrm{B} 1$ as test pieces, when the model was applied to other test pieces of the layering structure of the same type, certain differences were be caused due to the inherent errors and pasting process of the FBG sensors.

For the BP neural network mathematical model, increasing the training data can improve its accuracy. In this experiment, the error obtained by 50 sets of training data is within the set target value, so the BP neural network training process is convergent. By comparing the actual deflection value and the predicted deflection value of the four test pieces in Figure 6 and the magnitude of the root mean square error, It can be found that the BP neural network can be applied to the deformation reconstruction of CFRP laminated plate structure with higher consistency.

\section{Conclusion}

The basic principles and methods of BP neural network are first expounded in this paper. In line with the input and output relationship of the experimental objects, BP neural network algorithm was established in MATLAB. Based on the strain and deflection information of the upper surface of test pieces $\mathrm{A} 1$ and $\mathrm{B} 1$, on the basis of a large amount of experimental data, the BP neural network model between strain and deformation was learned and trained in MATLAB. The same experimental loading method was applied to the test pieces A2 and B2, and the changes of strain and deflection on the upper surface were collected and input into the BP neural network model. 
The BP predicted deflection of the neural network was compared with the actual measured deflection. The experiment proved that the BP neural network is capable of reconstructing the deformation of the CFRP laminate structure within certain error range.

\section{Acknowledgements}

This work was supported by the National Science Foundation of China (Project No. 51775400), Hubei Provincial Key Science and Technology Innovation Project (Project No. 2014AAA005) and The Fundamental Research Funds for the Central Universities (WUT: 2017III044).

\section{References}

1. Liu L, Jia C, He J, Zhao F, Fan D, Xing L, et al. Interfacial characterization, control and modification of carbon fiber reinforced polymer composites. Composites Science and Technology. 2015;121:56-72.

2. Kumar MSA, Panda S, Chakraborty D. Design and analysis of a smart graded fiber-reinforced composite laminated plate. Composite Structures. 2015;124:176-195.

3. Kumar A, Panda S, Kumar S, Chakraborty D. A design of laminated composite plates using graded orthotropic fiberreinforced composite plies. Composites Part B: Engineering. 2015;79:476-493.

4. LeBlanc B, Niezrecki C, Avitabile P, Chen J, Sherwood J, Hughes S. Full-field inspection of a wind turbine blade using three-dimensional digital image correlation. Proceedings of SPIE - The International Society for Optical Engineering. 2011;7979(1):79790L.

5. Lin HC. Layup Analyzing of a Carbon/Glass Hybrid Composite Wind Turbine Blade Using Finite Element Analysis. Applied Mechanics and Materials. 2011;87:49-54.

6. Xue L, Zhang J. Inspection, Maintenance and Repair of Composite Material Wind Turbine Blade. Wind Energy. 2012:7.

7. Li D, Ho SCM, Song G, Ren L, Li H. A review of damage detection methods for wind turbine blades. Smart Materials and Structures. 2015;24(3):033001.

8. Yang XW, Yu L, Lyu B, Guo H. Experiment on static aeroelastic models in high speed wind tunnel. Acta Aerodynamica Sinica. 2015;33(5):667-672.

9. Tessler A, Spangler JL. A least-squares variational method for full-field reconstruction of elastic deformations in sheardeformable plates and shells. Computer Methods in Applied Mechanics and Engineering. 2005;194(2-5):327-339.

10. Tessler A, Sciuva MD, Gherlone M. A Refined Zigzag Beam Theory for Composite and Sandwich Beams. Journal of Composite Materials. 2009;43(9):1051-1081.

11. Tessler A, Sciuva MD, Gherlone M. A consistent refinement of first-order shear deformation theory for laminated composite and sandwich plates using improved zigzag kinematics. Journal of Mechanics of Materials and Structures. 2010;5(2):341-367.
12. Gherlone M, Cerracchio P, Mattone M, Sciuva MD, Tessler A. Shape sensing of 3D frame structures using an inverse Finite Element Method. International Journal of Solids and Structures. 2012;49(22):3100-3112.

13. Cerracchio P, Gherlone M, Sciuva MD, Tessler A. Shape and Stress Sensing of Multilayered Composite and Sandwich Structures Using an Inverse Finite Element Method. European Physical Journal: D. 2013;66(11):1-9.

14. Cerracchio P, Gherlone M, Sciuva MD, Tessler A, et al. A novel approach for displacement and stress monitoring of sandwich structures based on the inverse Finite Element Method. Composite Structures. 2015;127:69-76.

15. Lu C F, Lu FD. Discussion on calculation method about the displacement of curved bars structure in structural mechanics. Mechanics in Engineering. 2016;38(1):90-92.

16. Frans R, Arfiadi Y, Parung H. Comparative Study of Mode Shapes Curvature and Damage Locating Vector Methods for Damage Detection of Structures. Procedia Engineering. 2017;171:1263-1271

17. Mosti F, Quaranta G, Lacarbonara W. Numerical and Experimental Assessment of the Modal Curvature Method for Damage Detection in Plate Structures. In: Belhaq M, editor. Structural Nonlinear Dynamics and Diagnosis. Berlin: Springer; 2015. p. 59-68.

18. Ko WL, Richards WL, Tran VT. Displacement Theories for In-Flight Deformed Shape Predictions of Aerospace Structures. Edwards, CA: NASA Dryden Flight Research Center; 2007.

19. Ko WL, Richards L, Fleischer VT. Applications of KO Displacement Theory to the Deformed Shape Predictions of the Doubly-Tapered Ikhana Wing. Edwards, CA: NASA Dryden Flight Research Center; 2009.

20. Jutte CV, Ko WL, Stephens CA, Bakalyar JA, Richards WL, Parker AR. Deformed Shape Calculation of a FullScale Wing Using Fiber Optic Strain Data from a Ground Loads Test. Edwards, CA: NASA Dryden Flight Research Center; 2011.

21. Hirwani CK, Panda SK, Patle BK. Theoretical and experimental validation of nonlinear deflection and stress responses of an internally debonded layer structure using different higher-order theories. Acta Mechanica. 2018;229(8):3453-3473.

22. Hirwani CK, Panda SK. Numerical and experimental validation of nonlinear deflection and stress responses of pre-damaged glass-fibre reinforced composite structure. Ocean Engineering. 2018;159:237-252.

23. Li H, Zhang Z, Zhao ZZ. Data-Mining for Processes in Chemistry, Materials, and Engineering. Processes. 2019;7(3):151.

24. Guihua Z, Xianmin M, Jing C. Improved BP neural networkbased back analysis of displacements. 2010 Second International Conference on Computational Intelligence and Natural Computing. Wuhan: IEEE; 2010. p. 374-377. Z, Xianmin M, Jing C. Improved BP Neural Network-Based Back Analysis of Displacements. Proceedings of 2010 Second International Conference on Computational Intelligence and Natural Computing (CINC 2010) Volume 1. Institute of Electrical and Electronics Engineers. 2010. 
25. Liu B, Wang L, Jin Y, Huang D. Designing Neural Networks Using Hybrid Particle Swarm Optimization. Lecture Notes in Computer Science. 2005;3496:391-397.
26. Geng XY, et al. Research on FBG-Based CFRP Structural Damage Identification Using BP Neural Network. Photonic Sensors. 2018;8(2):168-175. 